\title{
PERBANDINGAN KAPAL MONOHULL, CATAMARAN, TRIMARAN BERDASARKAN TINJAUAN OPERASIONAL PENGGUNAAN BAHAN BAKAR
}

\author{
Jacobus Tupan ${ }^{1, *}$, Richard Benny Luhulima ${ }^{2}$ \\ 1Jurusan Teknik Perkapalan Fakultas Teknik Universitas Pattimura, Ambon 97233 \\ *Email: jtupan@gmail.com \\ 2Jurusan Teknik Perkapalan Fakultas Teknik Universitas Pattimura, Ambon 97233 \\ Email: richardluhulima26@gmail.com
}

\begin{abstract}
Abstrak. Secara umum armada penangkapan ikan yang beroperasi di perairan Maluku dan dikelola oleh pengusaha lokal terdiri dari kapal penangkap ikan monohull dan trimaran dengan cadik. Kapal penangkap ikan monohull memiliki ruang geladak yang terbatas dan stabilitas melintang yang kurang baik, sedangkan kapal jenis trimaran memiliki ruang geladak yang lebih baik dan stabilitas melintang dibandingkan kapal monohull, namun karena masih dalam bentuk cadik maka ruangnya terbatas. Penelitian ini bertujuan untuk mengkaji perkembangan kapal penangkap ikan trimaran ditinjau dari kebutuhan energi, keselamatan dan kenyamanan awak kapal selama operasi penangkapan. Tahap awal penelitian ini diawali dengan analisis data dan ukuran pokok kapal penangkap ikan monohull yang beroperasi di perairan Maluku, dari data tersebut dirancang bentuk lambung kapal trimaran. Perhitungan hambatan dengan menggunakan CFD, kemudian dianalisis perhitungan hambatan dan stabilitas, keselamatan dan kenyamanan kapal dengan menggunakan Maxsurf. Kapal Trimaran hambatan memiliki 8,86\% lebih kecil dari monohull dan 3,25\% lebih kecil dari katamaran. Pengunaan Energi (EHP) terbukti kapal trimaran lebih dari mode kapal lainya. Periode trimaran rata-rata adalah 10,5 detik yang memenuhi standar IMO dan dinyatakan baik untuk operasional.
\end{abstract}

Kata kunci: CFD, Monohull, Catamaran, Trimaran, Fuel Use

\begin{abstract}
In general, fishing fleets operating in Maluku waters and managed by local entrepreneurs consist of monohull and trimaran fishing vessels with outriggers. Monohull fishing vessels have limited deck space and poor transverse stability, while trimaran-type vessels have better deck space and transverse stability than monohull vessels, but because they are still in the form of outriggers, the space is limited. This study aims to examine the development of the trimaran fishing vessel in terms of energy requirements, safety, and comfort of the crew during fishing operations. The initial stage of this research begins with data analysis and the basic size of monohull fishing vessels operating in Maluku waters, from this data the shape of the trimaran hull is designed. Calculation of resistance using CFD, then analyzed the calculation of resistance and stability, safety, and comfort of the ship using Maxsurf. The drag Trimaran is $8.86 \%$ smaller than a monohull and $3.25 \%$ smaller than a catamaran. Energy Usage (EHP) is proven by trimaran ships more than other ship modes. The average trimaran period is 10.5 seconds which meets IMO standards and is declared operationally good.
\end{abstract}

Keywords: CFD, Monohull, Catamaran, Trimaran, Fuel Use

\section{PENDAHULUAN}

Perairan Maluku merupakan perairan yang relatif tenang antara pulau-pulau yang berdekatan dan sangat bergelombang untuk laut lepas dan pulau-pulau yang relatif berjauhan. Dengan memiliki dua zona laut dengan karakteristik berbeda yaitu laut terbatas yang masih dikategorikan sebagai laut tenang karena ketinggian gelombang masih dibawah 1 meter. Di sisi lain, jalur pelayaran laut terbuka dengan kondisi iklim dan cuaca yang berubah sangat cepat serta ketinggian gelombang yang dapat mencapai ketinggian 3-5 meter cenderung menimbulkan ketidaknyamanan bahkan mengancam 
keselamatan kehidupan di laut. Jalur pelayaran yang sering menjadi perhatian banyak pihak baik Pemerintah maupun operator kapal adalah alur pelayaran dari Ambon ke Maluku Tenggara dan jalur pelayaran dari Ambon ke Pulau Halmahera, Maluku Utara yang harus dilalui jalur pelayaran laut lepas.

Sejalan dengan perkembangan teknologi desain kapal yang berkembang sangat pesat, dalam tiga puluh tahun terakhir ini terjadi banyak peningkatan permintaan kapal, baik kapal monohull, kapal dua badan (catamaran) maupun kapal tiga badan (trimaran). aplikasi untuk kapal penumpang (feri), fasilitas olah raga (sporting craft) dan kapal penelitian oseanografi serta kapal pukat [1]. Ketiga jenis kapal diatas masing-masing memiliki kelebihan dan kekurangan yang perlu diperhatikan saat akan kita gunakan.

Kapal monohull sudah ada sejak lama dan sudah banyak digunakan untuk kapal penumpang, pengangkut peti kemas dan kargo cair, kapal perang, dan lain-lain, lihat Gambar 1 (a). Jika dibandingkan dengan kapal monohull, kapal jenis katamaran memiliki beberapa keunggulan antara lain layout akomodasi yang lebih menarik, peningkatan stabilitas transversal dan dalam beberapa kasus mampu menurunkan daya dorong kapal untuk mencapai kecepatan layanan tertentu [2], lihat Gambar 1 (b). Pada Gambar 1 (c) Kapal Trimaran merupakan kapal multihull, terdiri dari satu main hull dan dua sidehull yang ukurannya cenderung lebih pendek dan terletak di kedua sisi main hull. Bentuk lambung kapal trimaran merupakan pengembangan dari bentuk lambung tunggal yang bertujuan untuk meningkatkan kecepatan kapal yang diikuti dengan pengurangan tenaga yang dibutuhkan. Investigasi terhadap lambung trimaran telah menunjukkan bahwa bentuk lambung trimaran memiliki hambatan yang lebih kecil pada kecepatan tinggi jika dibandingkan dengan lambung trimaran dan lambung tunggal.

\section{BAHAN DAN METODE \\ 2.1. Hambatan Kapal Monohull}

William Froude [3] pertama kali memperkenalkan hambatan kapal total yang terdiri dari dua komponen yaitu tahanan sisa dan gesekan. Hambatan sisa dalam hal ini meliputi komponen energi pembatas sistem pembuat gelombang, pusaran arus dan kehilangan energi kental akibat bentuk lambung kapal.

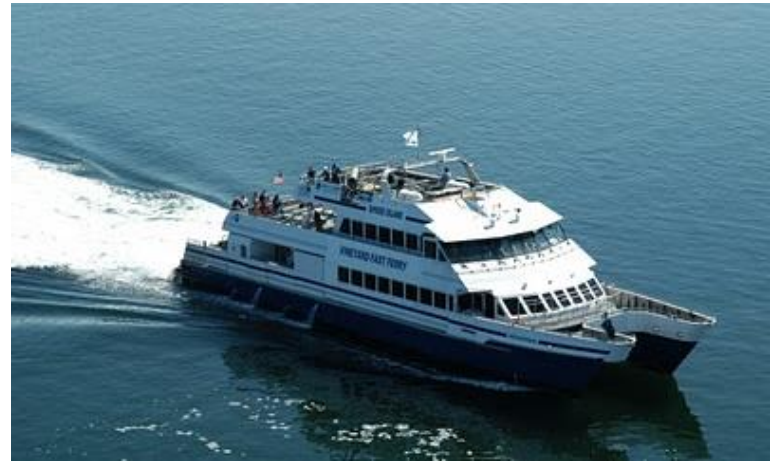

(b) Katamaran

(a) Monohull

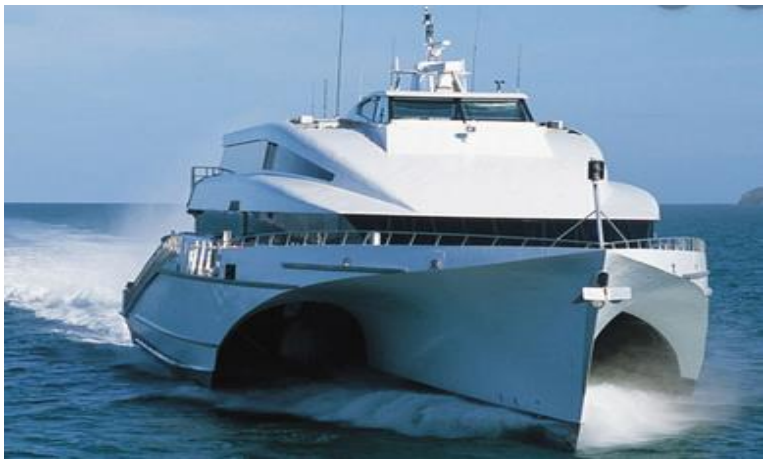

(c) Trimaran

Gambar 1. Tipe Kapal

Teknik Perkapalan | 31 
Sedangkan tahanan gesek kapal diasumsikan sama dengan tahanan gesek pelat datar 2 dimensi yang memiliki luas permukaan basah yang sama dan bergerak di air dengan kecepatan yang sama dengan kecepatan kapal.

$$
C_{T}=C_{F}+C_{R}
$$

Metode analisis 2 dimensi yang disebutkan di atas tidak cukup mencerminkan kontribusi bentuk / kontur lambung (yang merupakan 3 dimensi) terhadap tahanan kental, sehingga kemudian Hughes [4] memperkenalkan metode yang akan digunakan dalam model kapal. korelasi dimana resistansi total adalah jumlah dari 3 komponen:

a) Hambatan Gesek adalah gaya tegangan tangensial yang timbul antara molekul air dan lambung kapal, yang kemudian bertindak sebagai tahanan luas permukaan dengan luas dan panjang yang sama dengan model.

b) Hambatan bentuk adalah komponen hambatan yang dinyatakan dalam angka ' $\mathrm{k}$ ', yang merupakan hambatan di luar batas item di atas jika lambung kapal terendam cukup dalam.

c) Hambatan permukaan bebas sebagai hambatan gelombang (CW) merupakan hambatan yang timbul akibat pergerakan kapal relatif terhadap air sehingga timbul perbedaan tekanan pada permukaan basah kapal yang pada akhirnya menimbulkan pola gelombang. Hambatan gelombang adalah pengurangan hambatan total (CT) dari jumlah hambatan gesekan $(\mathrm{CF})$ dan hambatan bentuk (CF0) model.

$$
\begin{aligned}
& C_{T}=C_{F}+C_{F O}+C_{W} \\
& \operatorname{dimana} \\
& C_{F O}=k C_{F} \\
& C_{T}=(1+k) C_{F}+C_{W}
\end{aligned}
$$

$(1+\mathrm{k})$ disebut faktor bentuk dan dapat diperoleh dari percobaan pada kecepatan rendah $(\mathrm{Fr}<0.1)$ dimana $\mathrm{Cw}$ dapat diabaikan, sehingga faktor bentuk dapat dihitung dengan:

$$
(1+k)=\frac{C_{T}}{C_{F 0}}
$$

Selanjutnya standar internasional dari ITTC [5] mengklasifikasikan hambatan kapal di perairan tenang, secara praktis menjadi 2 (dua) komponen hambatan utama, yaitu tahanan kekentalan (viscous resistance) yang berhubungan dengan bilangan Reynolds dan hambatan gelombang yang bergantung pada bilangan Froude, dimana korelasi dari kedua komponen hambatan tersebut ditunjukkan pada persamaan di bawah ini.

$$
C_{T}=(1+k) C_{F}+C_{W}
$$

\subsection{Hambatan Kapal Katamaran}

Hambatan kapal katamaran memiliki fenomena yang lebih kompleks daripada monohull, akibat pengaruh interferensi dan interaksi antara kedua lambung kapal.

Interferensi lambung adalah aliran simetris air di sekitar lambung (demihull) yang asimetris akibat interaksi aliran antar lambung, yaitu besarnya tekanan yang timbul di sekitar lambung relatif simetris terhadap garis tengah lambung. Periksa apakah laju aliran di sekitar lambung (demihull) meningkat, terutama di area dalam (sisi terowongan). Peningkatan kecepatan menyebabkan peningkatan ketahanan gesekan kulit dan mengubah faktor fom. Ketinggian ombak di punggung batang dalam dan luar berbeda, sehingga aliran air pada batang menunjukkan arah ke dalam atau ke luar. Ini menghasilkan percikan/sibakan di bagian belakang lambung yang pada gilirannya menciptakan komponen tarikan.

Intereferensi gelombang terjadi pada lambung kapal katamaran yang bergerak berdampingan pada kecepatan tertentu, sehingga dapat diamati pengaruh interferensi dan interaksi hambatan gelombang yang dihasilkan. Karena perubahan tekanan lingkungan, hal itu menyebabkan gelombang. Di demihull bisa berubah. Dengan kata lain, formasi gelombang lambung dapat berbeda dengan lambung terisolasi. Interaksi gelombang yang disebabkan oleh lambung dapat terjadi. Gelombang transversal dari satu lambung kapal selalu diperkuat oleh yang lain, sedangkan gelombang hamburan yang terjadi di depan (haluan) salah satu lambung dapat dinegasikan dengan hamburan gelombang di belakang (batang) dari sisi lain atau dengan pantulan yang sama. gelombang depan dari sisi lain.

Dari uraian tersebut terlihat bahwa pengaruh interferensi viskos dan gelombang sangat signifikan pada kapal katamaran. Interferensi viskos disebabkan oleh aliran asimetris di sekitar lambung kapal yang mempengaruhi pembentukan lapisan batas, sedangkan gangguan gelombang disebabkan oleh interaksi gelombang yang dihasilkan oleh masing-masing lambung.

Pada bagian ini, komponen koefisien interaksi hambatan pada demihull (katamaran) dijelaskan sebagai berikut: 


$$
\begin{aligned}
\left(C_{T}\right)_{C A T} & =\left(1+k_{C A T}\right)\left(C_{F}\right)_{C A T}+\left(C_{W}\right)_{C A T} \\
& =(1+\emptyset k) \sigma C_{F}+\tau C_{W}
\end{aligned}
$$

Dimana:

$\varnothing=$ gangguan faktor bentuk, yang disebabkan oleh perubahan tekanan yang terjadi antara kedua lambung kapal

$\sigma=$ faktor interferensi gesekan (friction) yang disebabkan oleh terjadinya peningkatan kecepatan aliran antara kedua lambung kapal.

$\tau=$ faktor interferensi hambatan gelombang (wave) yang disebabkan oleh pertemuan dua mode gelombang (haluan) antara kedua lambung.

\subsection{Hambatan Kapal Trimaran}

Fitur desain yang disempurnakan dari trimaran mengarah pada pengurangan hambatan sisa, namun konsekuensinya adalah bentuk hambatan baru: posisi dekat lambung terpisah mengarah ke interaksi hambatan total.

Hambatan total untuk lambung trimaran adalah $\mathrm{R}_{\mathrm{T}}$ pada mainhull dan dua resistansi yang sama pada sidehull $\mathrm{R}_{\text {TSidehull }}$ and $\mathrm{R}_{\text {Tmainhull, }}$ yang dirumuskan menjadi:

$$
\mathrm{R}_{\mathrm{T}}=2 \mathrm{R}_{\mathrm{TSidehull}}+\mathrm{R}_{\mathrm{TMainhull}}
$$

Seperti disebutkan, interaksi gelombang disebabkan oleh posisi berbagai lambung dengan mengacu pada pemisahan, yang menyiratkan bahwa jika lambung diposisikan sedemikian rupa sehingga tidak ada interaksi antara lambung, maka tidak ada hambatan interferensi yang akan dialami. Dengan menyelidiki variasi pemisahan, hambatan interferensi ini dapat dikurangi, dihilangkan, dan bahkan dimanfaatkan. Hal yang menarik adalah bahwa meskipun interferensi akan menyebabkan lambung menjadi tidak efisien, ada beberapa posisi ketika interferensi tersebut menghasilkan situasi yang menguntungkan ketika dan kapal lengkap akan mengalami hambatan yang lebih kecil daripada penambahan lambung individu yang bertindak secara terpisah.

Resistensi interferensi ini dapat dihitung, sedemikian rupa sehingga:

$$
\begin{aligned}
& \mathrm{R}_{\mathrm{T}}=3 \mathrm{R}_{\mathrm{THull}}+\Delta \mathrm{R}_{\mathrm{TV}}+\Delta \mathrm{R}_{\mathrm{TW}} \\
& \mathrm{R}_{\mathrm{T}}=3 \mathrm{R}_{\mathrm{THull}}+\mathrm{R}_{\text {interfernce }}
\end{aligned}
$$

di mana $\triangle \mathrm{RTV}$ dan $\triangle \mathrm{RTW}$ dapat dikelompokkan sebagai interferensi hambatan kapal trimaran ( $\left.\mathrm{R}_{\text {interfernce }}\right)$.

Rumusan empiris untuk memperkirakan hambatan total trimaran sejauh ini belum diketahui dan sangat bergantung pada hasil eksperimen. Ini juga dikaitkan dengan publikasi minimum tentang resistensi trimaran baik secara eksperimental maupun numerik.

\section{HASIL DAN PEMBAHASAN 3.1. Hambatan Kapal}

Hasil perhitungan hambatan menunjukkan bahwa kapal dengan lambung trimaran memiliki hambatan yang paling kecil. Dengan daya tahan 98,5 kN dengan kecepatan 12 knot. Hambatan kapal Trimaran memiliki selisih rata-rata 9,4\% dengan kapal monohull dan 2,3\% terhadap kapal katamaran (Pada Tabel 2 nilai negatif menunjukkan harga yang lebih kecil dibandingkan kapal pembanding).

Perhitungan Engine Effective Power (EHP) juga menunjukkan kecenderungan yang sama, yaitu kapal trimaran membutuhkan daya paling kecil diantara kapal pembanding lainnya. Hal tersebut ditunjukkan pada Gambar 2, dimana kapal Trimaran dengan kecepatan 12 knot membutuhkan tenaga sebesar $608,08 \mathrm{~kW}$, sedangkan kapal katamaran membutuhkan tenaga $629,16 \mathrm{~kW}$, dan kapal monohull membutuhkan tenaga 665,43 kW. Hal ini menunjukkan kapal trimaran memiliki keunggulan dalam menggunakan tenaga mesin yang lebih sedikit, seperti ditunjukkan pada Gambar 2.

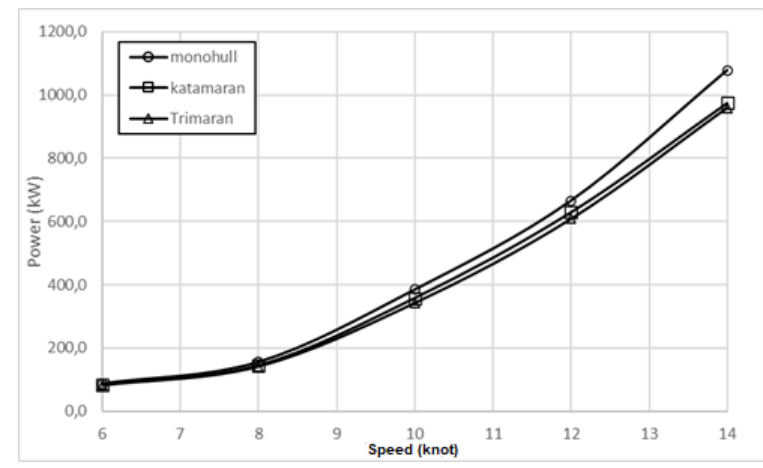

Gambar 2. Kosumsi Bahan Bakar 
Tabel 2. Hambatan Total

\begin{tabular}{ccccccc}
\hline $\begin{array}{c}\text { Speed } \\
(\mathrm{knot})\end{array}$ & \multicolumn{3}{c}{ Resistance $(\mathrm{kN})$} & \multicolumn{3}{c}{ Perbedaan $(\%)$} \\
\cline { 2 - 7 } & Monohull & Catamaran & Trimaran & $\begin{array}{c}\text { Monohul- } \\
\text { Catamaran }\end{array}$ & $\begin{array}{c}\text { Monohull- } \\
\text { Trimaran }\end{array}$ & $\begin{array}{c}\text { Catamaran- } \\
\text { Trimaran }\end{array}$ \\
\hline 6 & 28.3 & 27.2 & 26.9 & -3.8 & -5.1 & -1.1 \\
8 & 37.8 & 35.1 & 34.7 & -7.1 & -8.9 & -1.3 \\
10 & 74.7 & 69.5 & 66.6 & -6.9 & -11.7 & -4.2 \\
12 & 107.8 & 101.9 & 98.5 & -5.4 & -9.1 & -3.4 \\
14 & 149.7 & 135.4 & 133.2 & -9.5 & -12.2 & -1.7 \\
\hline \multicolumn{7}{c}{ Average } \\
\hline
\end{tabular}

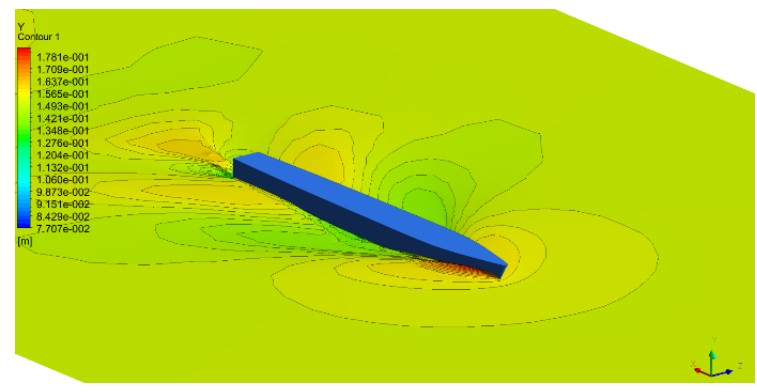

(a) Monohull

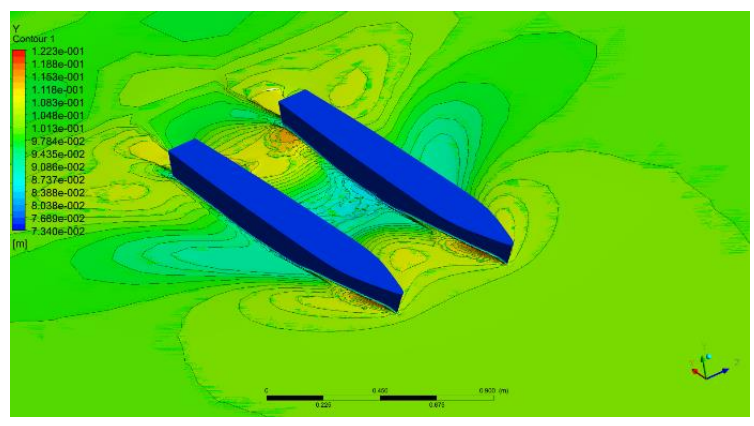

(b) Katamaran

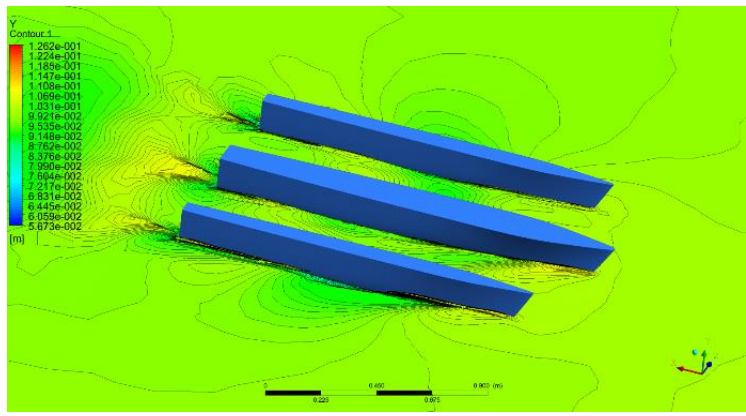

(c) Trimaran

Gambar 3. CFD Simulation of Ship

Bentuk flat hull atau thin ship hull (L / B >>), kontribusi hambatan gelombang lebih besar dari pada hambatan gelombang terhadap hambatan total. Resistensi kental (yang didominasi oleh resistensi gesekan) meningkat dengan bertambahnya panjang lambung. Dengan bertambahnya panjang atau luas area basah maka gaya gesek permukaan juga akan meningkat. Sedangkan untuk tahanan gelombang pada umumnya menjadi lebih kecil dengan bertambahnya panjang lambung kapal (untuk displacement tetap).

\subsection{Estimasi Konsumsi Bahan Bakar dan Biaya Operasional}

Konsumsi bahan bakar di kapal dapat diperkirakan dengan rumus berikut.
Fuel Consumption $=\frac{P_{S} \times b_{m e} \times C_{R} \times 10^{-6}}{V_{S}}$

Dimana Ps adalah tenaga kapal $(\mathrm{kW})$, bme adalah bahan bakar spesifik (bme oil = $135 \mathrm{~g} / \mathrm{BPHPh}$ ), CR adalah jarak jelajah (nautical miles) dan Vs adalah kecepatan kapal (m/s).

Perhitungan konsumsi bahan bakar tenaga kapal dalam perhitungan ini diambil nilai konsumsi bahan bakar spesifik $135 \mathrm{~g} / \mathrm{BHPh}$. Nilai ini dianggap sebagai batasan masalah. Perhitungan. Tenaga yang didapat dari perhitungan merupakan daya efektif (EHP) sehingga untuk perhitungannya harus dicari daya horsepower (BHP) yang merupakan tenaga yang harus dikeluarkan oleh mesin untuk mencapai daya dorong efektif. 
Tabel 3. Perhitungan konsumsi bahan bakar dan biaya operasional

\begin{tabular}{ccccccc}
\hline \multirow{2}{*}{$\begin{array}{c}\text { Speed } \\
(\mathrm{kn})\end{array}$} & \multicolumn{2}{c}{ Konsumsi Bahan Bakar (Ton) } & \multicolumn{3}{c}{ Operational Cost (USD) } \\
\hline 6 & Monohull & Catamaran & Trimaran & Monohull & Catamaran & Trimaran \\
\hline 8 & 1.91 & 1.84 & 1.82 & 120.2 & 115.5 & 114.2 \\
10 & 2.55 & 2.37 & 2.34 & 160.5 & 149.1 & 147.2 \\
12 & 5.04 & 4.69 & 4.49 & 317.2 & 295.2 & 282.8 \\
14 & 7.28 & 6.88 & 6.65 & 457.7 & 432.8 & 418.3 \\
\hline Average & 10.0 & 9.14 & 8.99 & 635.6 & 575.1 & 565.4 \\
\hline
\end{tabular}

Tenaga yang didapat adalah maximum continuous range (MCR) dari mesin yang akan digunakan. Hasil perhitungan konsumsi bahan bakar dan rasio bobot DWT. Harga solar untuk kapal masih berfluktuasi dengan kisaran harga Rp 0.63 Perhitungannya pun dilakukan dengan jarak pelayaran 500 mil.

Perhitungan konsumsi bahan bakar dan biaya operasional kapal ditunjukkan pada Tabel 3. Kapal Trimaran memiliki rata-rata konsumsi bahan bakar terkecil yaitu 4,86 ton, sedangkan untuk katamaran sebesar 4,98 ton dan pada monohull 5,38 ton. Hal ini menunjukkan bahwa kapal trimaran memiliki keunggulan konsumsi bahan bakar yang rendah (hemat).

Hal ini berkorelasi dengan biaya operasional kapal. Seperti yang ditunjukkan pada Tabel 3, Biaya Operasional (Konsumsi Bahan Bakar) adalah USD305.6 untuk kapal trimaran dan USD313.5 untuk kapal Catamaran dan USD338.2 untuk kapal monohull. Kapal Trimaran membutuhkan biaya operasional paling sedikit dibandingkan jenis kapal lainnya.

\section{KESIMPULAN}

Perhitungan biaya operasional kapal berdasarkan konsumsi bahan bakar diperoleh dari hasil perhitungan lindung nilai kapal dan dapat disimpulkan sebagai berikut:

1. Kapal Trimaran memiliki hambatan terkecil yaitu 98,5 kN dengan kecepatan 12 knot. Hambatan kapal Trimaran memiliki perbedaan rata-rata $9,4 \%$ dengan kapal monohull dan 2,3\% terhadap kapal katamaran.

2. Konsumsi Bahan Bakar dan Biaya Operasi Kapal ditunjukkan pada Tabel 4.5. Kapal Trimaran memiliki konsumsi bahan bakar rata-rata terkecil 4,86 ton, sedangkan katamaran 4,98 ton dan monohull 5,38 ton.
3. Biaya Operasional (Konsumsi Bahan Bakar) USD305.6 di kapal trimaran; Rp. USD313.5 untuk kapal Catamaran dan USD338.2 untuk kapal monohull. Kapal Trimaran membutuhkan biaya operasional paling sedikit dibandingkan jenis kapal lainnya. Kapal Trimaran memiliki potensi yang cukup baik untuk dikembangkan sebagai kapal pengangkut penumpang di perairan Maluku

\section{UCAPAN TERIMA KASIH}

Penulis mengucapkan terima kasih kepada Universitas Pattimura yang telah mendanai pekerjaan saat ini

\section{DAFTAR PUSTAKA}

[1] M. Javanmardi, E. E. Jahanbakhsh, M. Seif, and H. Sayyaadi, "Hydrodynamic Analysis of Trimaran Vessels," Polish Maritime

Research, vol. 15, no. 1, pp. 11-18, Jun. 2008, doi: 10.2478/v10012-007-0046-5.

[2] M. Insel and A. F. Molland, "an Investigation into the resistance components of high speed displacement catamarans," 1992, Accessed: Aug. 10, 2021. [Online]. Available: https://trid.trb.org/view.aspx?id=440256

[3] W. Froude, "William Froude," Nature, vol. 20, no. 502, pp. 148-150, Jun. 1879 , doi: 10.1038/020148a0.

[4] G. Hughes, "Friction and form resistance in turbulent flow, and a proposed formulation for use in model and ship correlation," National Physical Laboratory, NPL, Ship Division, Presented at the Institution of Naval Architects, Paper No. 7, London, April, RINA Transactions 1954-16, 1954, Accessed: Aug. 10, 2021. [Online]. Available: https://repository.tudelft.nl/islandora/object/u uid\%3A9a642c53-27f0-45fe-a5e45e1296b62af1 
[5] ITTC, "ITTC - Recommended Procedures;

Testing and Extrapolation Methods

Resistance Resistance Test.” ITTC, 2002.

[Online]. Available:

https://ittc.info/media/2019/75-02-02-01.pdf 